never could be reduced), but is some small fraction of an ohm (say, .2 ohm), and suppose that there is a single lamp of $140 \mathrm{ohms}$ ' resistance in circuit, and that the electromotive force is 100 volts: then

$\frac{140}{140.2} \times 100=99 \frac{6}{7}$ volts will be the fall of potential in the lamps, and only $q$ volt in the armature. But suppose that there are 70 lamps of the same re. sistance (140 ohms) in circuit, instead of a single one: then the external resistance will be reduced to 140
70 $70=2 \mathrm{ohms}$, and the fall of potential in the lamps will only be $\frac{2}{2.2} \times 100=90 \frac{10}{11}$ volts, and $9 \frac{1}{1}$ volts in the armature.

Thus we see, that, when the number of lamps in circuit is increased from 1 to 70 , the difference of potential available in the lamps is decreased from $99 \%$ to $90 \frac{1}{1} 1$ volts, a reduction of almost one-tenth; in consequence of which the candle-power of the lamps would be lowered at least one-third, and probably one-half. Of course, variations in the brightness of the lamps of one-third, or one-tenth, or even one-twentieth, would not be permissible: therefore, in order to maintain the required steadiness of the light, it is necessary to raise the electromotive force of the dynamo as more lamps are put on, and to lower it as lamps are taken off. This is done by increasing or diminishing the strength of current in the circuit of the field-magnets by means of a resistance-box interposed in the circuit. This regulation of the electromotive force of dynamos by controlling the resistance of the field-circuit may be, and in fact has been, made automatic; but up to the present time it has more generally been done by hand.

In what has gone before, I have said nothing about the resistance of the conductors which convey the current from the dynamo to the lamps. The effect of the resistance of any conductor which is common to two or more lamps - one of the main conductors, for example - is precisely the same as the effect of the resistance of the armature, which has been discussed above; but when a conductor supplies only a single lamp, then it does not have this effect. Of course there is a loss or fall of potential due to the resistance of the individual conducting-wires of each lamp; and of course the fall of potential in the lamp itself, and consequently its brightness, are thereby reduced. But this resistance does not introduce any irregularity: its effect in diminishing the light of the lamps is constant.

Let us suppose that a conductor having a resistance of $140 \mathrm{ohms}$ feeds a single lamp of $1.4 \mathrm{ohms}$ ' resistance: then the loss in this conductor will be $1 \%$ of the useful fall of potential. But suppose that we now put 10 more lamps in circuit: then the loss in the conductors will be increased to over $10 \%$; and assuming the useful fall of potential to be 100 volts, with a single lamp in circuit, it will only be about 90 volts with 11 lamps. The candle-power of the first lamp would drop at least $25 \%$ or $30 \%$ when the other 10 lamps were added. 'Thus it is,' that, in a multiple arc system of electric lighting, any resistance which is common to a number of lamps, whether in the armature or the conductors, causes fluctuations in the light of the lamps when other lamps are put on or off; whereas the resistance of the individual conductors of each lamp produces a loss of potential which is a constant fraction of the total potential, but does not introduce any unsteadiness.

F. B. Crocker.

\section{Osteology of the cormorant.}

With respect to Mr. Jeffries' criticism (ScIEnce, ii. 739) of my paper on cormorants, I beg to say that the occipital style of the cormorant is not an ossification in the tendon of any muscle; that he is entirely wrong in his view of the homologies of what I call a patella; and that, furthermore, I find myself misquoted more than once.

R. W. SHUF ELDT.

\section{A dog plans and executes with reference to the future.}

Six weeks ago Prof. J. B. Thayer of this place returned from Ree Heights, Dakota, bringing with him one of a litter of eight pups raised by a slut of the setter breed. The story which he relates to me of this pup's mother is, it appears to me, worthy of record.

'The good mother appears to have discharged her arduous duties as only a mother can, and arrived with her eight babes at the time when they should be weaned. At this juncture, judging from the events reported to have followed, she seems to have conceived the idea that too many dogs were occupying the same claim, and that a distribution was desirable. Accordingly, she started one morning with three of her pups, and was observed by Miss Rosa Cheney, now of this place, running in the road toward their claim at a rate which made it impossible for the pups to keep pace with her. The dwelling where she lived, and another shanty on the adjoining corner of another claim, are situated one mile and three-fourths from the dog's home. The mother reached the claims in advance of her babes, but no sooner had they arrived than she hurried on at her best pace. Miss Cheney reports that " the puppies came up all out of breath, and apparently too tired to continue; but the smallest of the three followed on." Another claim was reached three-fourths of a mile beyond; and here Miss Cheney observed the mother stop until her panting babe came up, when she immediately set off again. A quarter of a mile beyond the last claim, the mother was observed to make a third halt as before, and then to pass on beyond the range of vision, towards Ree Heights, with the puppy still following her. Two days later the persistent mother, with her more persistent babe, was observed coming back; and Miss Cheney tells me that the little puppy appeared almost dead from fatigue.

Some days later the dog led off two more of her pups, and succeeded in leaving them both; but in the mean time the two puppies left the first day were returned. A pup was also left at Professor Thayer's claim, but was returned, and exchanged for another. Both Professor Thayer and Miss Cheney assure me that other efforts of the same kind were made by this dog, but with what results they are unable to say.

After the puppies had been distributed, they were not forgotten; for the old dog used often to go and play with them. Professor Thayer mentions one instance of her coming and playing with the puppy left at his claim until it was very tired, when she lay down by the side of it; but, after it had gone to sleep, she quietly walked to the opposite side of the house, and then hurried away in the opposite direction from home for a distance of about forty rods, when she turned and went directly there, thus showing quite clearly that the thought of distributing her puppies was still uppermost in her mind.

What events may have awakened this desire on the part of the mother, or what reasons she had for her acts, we do not know; but in her own mind I have no doubt the case was urgent and the way clear, if 
not also just. It would appear, not only that this dog must have thought her plan through, but that she must also have held it definitely in mind for several days while she executed it, thus indicating quite unequivocally, it seems to me, that one animal at least, ranked lower than man, possesses the power of looking into the future and of executing plans deliberately laid with reference thereto; "man is the only animal which has the power of looking into the future," to the contrary notwithstanding.

River Falls, Pierce county, Wis.

\section{Method for making electrical signals.}

When I first became connected with the Alabama agricultural and mechanical college, the recitation signals were made by means of electric bells, one in

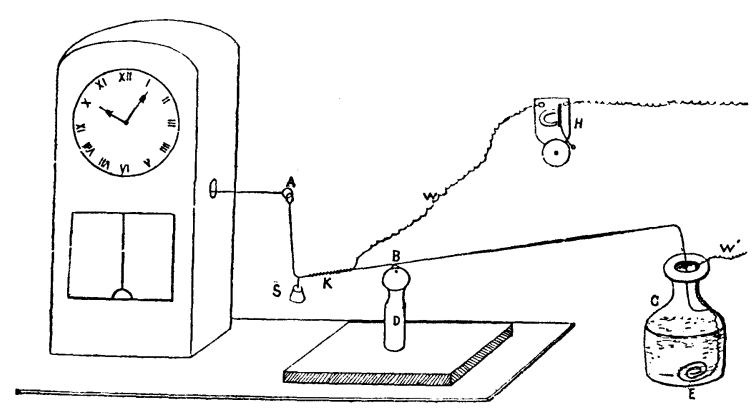

Frg. 1.

each professor's room. These were rung separately by pressing in succession as many push-buttons as there were bells. In order to complete the system, it was necessary to have one wire for each bell, and a return-wire running through the whole length of the system; and therefore only one bell could be rung at once. In the circuit there were twelve bells, about one-half mile of wire, and twelve one-gallon cells of Watson's battery. One of the cadets of the college was delegated to sound the signals at the end of each fifty minutes, which was the length of the recitation hours. Sometimes he would ring too soon, and at other times several minutes too late. This was frequently annoying, particularly when an interesting

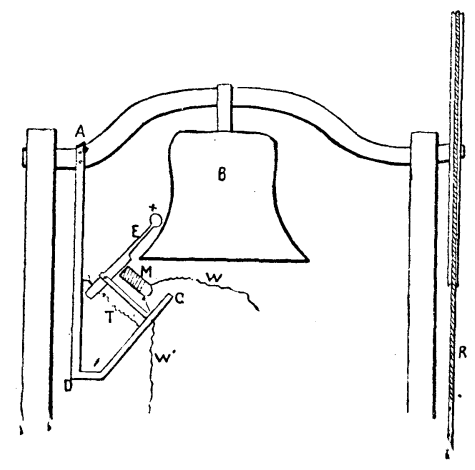

FIG. 2.

and important lecture was in progress. In the attempt to obviate this difficulty, the plan that I am about to describe was suggested to my mind.

We have an excellent compensated clock that can be made to strike twice any multiple of five minutes. After adjusting this clock so as to make it strike every fifty minutes, 1 insulated it on a square of plate glass. I then made an oblong opening in the side of the woodwork about one inch long. This slit was made on a line with the ball of the striker. Through this hole I passed a copper wire, and fastened it securely to the hammer of the gong. In the end of the wire outside of the clock I made a loop, as shown at $A$, Fig. 1 .

A second wire, $A B C$, was attached to the first, as shown in the figure. A loop at $B$ fits in a slit in the upright $D$, and a pin is inserted at $B$ to hold the wire in position and at the same time allow the ends $A$ and $C$ to work up and down when the hammer of the clock strikes. The bottle $C E$ is partly filled with mercury. From this mercury-cup a wire, $E W^{\prime}$, runs to one pole of the battery. 'The other pole connects at $K$ with the wire $W$, after passing through all the bells of the system. $S$ is a weight to counterbalance the arm $B \dot{C}$. It will be readily seen that the outward stroke of the hammer will throw the end of wire $A B C$ into the mercury, thus completing the circuit, and causing all the bells to ring. The blow of the hammer against the gong of the clock will raise the end $C$, and break connection. All but one of the bells must be single stroke: otherwise it will be impossible to obtain satisfactory results. By using one bell, with attachment for breaking and closing the circuit, the ringing will continue as long as the wire at $C$ is in contact with the mercury.

The above system has been in operation for one year, and has given satisfactory results.

It has occurred to me that our large bell, weighing nearly two thousand pounds, can be made to strike the hours for the benefit of the town by placing it in the system just described, with the following adjustment. Procure a soft iron horseshoe magnet six or eight inches long, and secure it at $\boldsymbol{M}$ on the iron rod $A D C$, Fig. 2. 'This becomes magnetized when the clock completes the circuit. The armature $X Y$ is attracted, and the ball $X$ strikes the bell. The elasticity at $E$ raises the ball immediately from contact, and allows a clear and distinct ring. The tensionspring $T$ raises the armature from the magnet, and the current ceases to flow. If it is desirable at any time to ring the bell in the ordinary way by means of the rope $R$, the adjustment of the system may be sustained by making the supporting rod $A D C$ secure to the bell-shaft at $A$, and thus permitting the magnet and fixtures to swing with the bell.

Auburn, Ala. P. H. MELI, Jun.

\section{GEIKIE'S GEOLOGY.}

Text-book of geology. By Archibald Geikie, LL.D., F.R.S., director-general of the Geological survey of Great Britain and Ireland, etc. With illustrations. London, Macmillan \& Co., 1882. 971 p. $8^{\circ}$.

TExT-Books in science once held a rather low place in the estimation of scientific men. Labor of this sort was long relegated to the book-makers, who, copying statements and illustrations one from another, gave the student more of the errors of by-gone days than of the knowledge of their own. But in our own time all this has been greatly bettered. Now a man 